\title{
Potential Effects of the Affordable Care Act on the Award of Life Care Expenses
}

\author{
By \\ Joshua Congdon-Hohman and Victor A. Matheson
}

September 2012

COLLEGE OF THE HOLY CROSS, DEPARTMENT OF ECONOMICS

FACULTY RESEARCH SERIES, PAPER NO. 12-01*

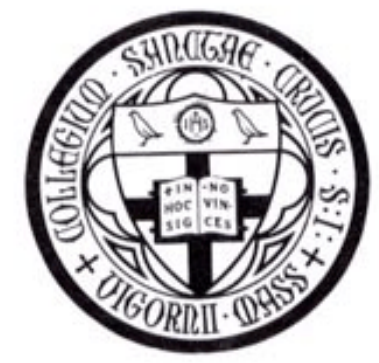

Department of Economics

College of the Holy Cross

Box 45A

Worcester, Massachusetts 01610

(508) 793-3362 (phone)

(508) 793-3708 (fax)

http://www.holycross.edu/departments/economics/website

*All papers in the Holy Cross Working Paper Series should be considered draft versions subject to future revision. Comments and suggestions are welcome. 


\title{
Potential Effects of the Affordable Care Act on the Award of Life Care Expenses
}

\author{
Joshua Congdon-Hohman ${ }^{\dagger}$ \\ College of the Holy Cross \\ and \\ Victor Matheson ${ }^{\dagger \dagger}$ \\ College of the Holy Cross
}

September 2012

\begin{abstract}
Plaintiffs in personal injury lawsuits are entitled to compensation for future medical expenses. We argue that the "guaranteed issue" and "individual mandate" requirements of the recently passed Affordable Care Act (ACA) will allow victims to address their health needs through the purchase of a simple health insurance plan rather than direct compensation for an itemized list of health care needs. As such, damage awards for health expenditures should be capped at a maximum of $\$ 5,950$ per year. Furthermore, the role of a life care planner should evolve into determining which life care expenses are covered under covered by the minimum insurance requirements mandated by the ACA and which entail additional expenditures beyond those covered by health insurance.
\end{abstract}

JEL Classification Codes: I13, I18, K41

Keywords: Health insurance, forensic economics, Affordable Care Act, tort reform

'Department of Economics, Box 72A, College of the Holy Cross, Worcester, MA 01610-2395, 508-793-3673 (phone), 508-793-3708 (fax), jcongdon@holycross.edu

"Department of Economics, Box 157A, College of the Holy Cross, Worcester, MA 01610-2395, 508-793-2649 (phone), 508-793-3708 (fax), vmatheso@ holycross.edu 


\section{Introduction}

In the context of personal injury and wrongful death cases, the task of the forensic economist is to determine the economic damages to the plaintiff associated with an act of negligence on the part of the defendant. While many potential areas of economic losses exist, two primary areas of damage are a part of many cases: lost compensation and medical costs. As the overriding goal of civil proceedings is to "make the victim whole," in both areas it is critical to identify the income or expenses that a plaintiff would have expected prior to an act of negligence and compare these figures to the income or expenses that a plaintiff can expect after the accident. In this paper, we plan to address how the Affordable Care Act (ACA) could potentially impact the estimation of those expenses. 1

This concept of expected economic costs and benefits both before and after is most commonly seen in estimates of lost wages. Essentially all experts' reports in cases involving death, injury, or wrongful termination will include an estimate of the expected earnings of the victim had the event not occurred based on some combination of past work history, individual depositions, and/or socio-demographic variables. Any honest practitioner of forensic economics will also include an estimate of the victim's earnings after the accident, often with the assistance of vocational experts. Compensation that the victim is still capable of earning, should any be found to exist, is used to offset the compensation losses estimated previously.

In theory the same idea should apply to life care plans that are formulated by medical experts in response to accidents where the victim will require care and treatment for an extended

1 ACA is the commonly used reference term for a pair of 2010 laws that were meant to reform the health insurance payment system in the United States. The two bills were the "Patient Protection and Affordable Care Act" and the 
period beyond the time of the trial. Only medical and living expenses that are necessary but would not otherwise have been required in the absence of the accident should be compensated. This so-called "but for" principle is not as uniformly applied in life care plans as in lost earnings, but there are plenty of examples of its application in these settings. Victims with limited mobility often require wheelchair accessible housing; however, "but for" their accident they still would have required some type of housing. The proper compensation should therefore be the cost difference between handicapped accessible housing and non-accessible housing of a similar size and quality or more simply the cost of home modifications to convert an existing house into an accessible one. One commonly sees this approach in life care plans, even those produced on behalf of the plaintiff. A similar rule should apply to transportation. An accident does not alter one's need or desire to be able to drive somewhere, but it does increase the cost of available transport. In this case, the cost of vehicle modifications is a better estimate of the "but for" criteria than the entire cost of a handicapped accessible vehicle. The "but for" principle also explains why routine dental care, a necessary medical service, is generally excluded from life care plans. While dental care is undoubtedly medically necessary for injured patients, it is equally necessary for uninjured individuals, and in the vast majority of personal injury cases, the accident cannot be shown to have increased the expense or necessity of proper dental care.

One generally sees the "but for" principle applied far less often to medical services and other common portions of life care plans. Often routine medical visits are included as part of a life care plan. Arguably, all persons should be partaking in routine medical visits, but these

"Health Care and Education Reconciliation Act of 2010." Most of the law was upheld as constitutional by the United States Supreme Court in 2012 (Liptak 2012). 
expenses are rarely challenged by economic experts presumably on the basis that one could argue that routine visits are more medically necessary for a severely injured patient than for an average person.

Applying the "but for" principle strictly, several deductions could be applied to the life care expenses of critically injured. If a life care plan recommends institutionalization, many facilities have single price that includes food, lodging, and utilities. Of course, "but for" the accident, the victim would have still required food and shelter, so applying the economic principle strictly, it would be reasonable to subtract the cost of a subsistence level of survival from the price tag of the institution. In effect, the cost of the accident is not the cost of the facility, say $\$ 150,000$ per year, but instead the difference between the expensive accommodations now required and the cheaper living expenses that the victim would have required should he or she not have become a victim. One proxy for a subsistence level of living expenses might be the poverty rate for a single individual equal to $\$ 10,890 /$ year in 2011 . Similarly, life care plans for individuals who are tube fed usually include the price of the nutrition supplements used. Again, a strict application of the "but for" principle would argue that the accident is not responsible for the victim requiring food, only for the type of food required, and the cost of a basic nutritionally required diet could be subtracted from the life care plan. Of course, in both cases, trial strategy may preclude such actions as the explanation of the calculations would serve to highlight the severity of the victim's injuries and would make it particularly easy for opposing counsel to paint the economic expert as a particularly heartless beancounter. 


\section{Health Insurance and Medical Costs prior to the ACA}

Health insurance potentially complicates the economic application of the "but for" principle and introduces legal complications. Unlike expenditures on housing or transportation, the typical American purchases few medical services directly with out-of-pocket funds. According to the Center for Medicare and Medicaid Services, only $12 \%$ of health care expenditures in the U.S. are out-of-pocket while $72 \%$ of health care services are paid for through a combination of private and public health insurance (Martin et al. 2012). Traditionally, health insurance is acquired through an employer (one's own or that of a family member), the government (through such programs as Medicare, Medicaid, or veterans benefits), or direct purchase from an insurer.

It may therefore be worth asking why life care plans should include specific medical expenses rather than a simple line item for health insurance that could be purchased and would provide for any health care costs. The answer is that it was unlikely that an injured party would have adequate access to health insurance markets under the health insurance system that existed in the U.S. prior to 2009. We will explore a number of reasons why it was unreasonable to assume an individual could receive health insurance benefits from one of the traditional sources after an injury.

It is impractical to assume a victim will be able to pay for future health care costs from employer provided health insurance. First, a plaintiff may not be employed at a job with health insurance benefits and may have little hope of obtaining employment in an occupation that provides such benefits. Surveys have found that the offer rate of employer provided health insurance has fallen in recent decades. For example, a 2007 survey found that 60 percent of 
employers offered health insurance to their employees, which was down from 69 percent in 2000 (Kaiser Family Foundation and Health Research and Education Trust, 2007). Second, even if a worker did have health insurance prior to an accident, in many cases injuries prevent the victim from returning to work in that field. Indeed, loss of employability is a prime motivation for filing a lawsuit in the first place. Finally, even those plaintiffs with insurance who are able to continue working have no guarantee that they will continue to be employed by the same firm, have no guarantee that the firm will continue to offer health insurance benefits, and should not be subject to "job lock" simply to avoid losing health insurance. Similar issues exist for plaintiffs who would normally be covered under the health insurance of a parent or spouse.

It is also impractical to presume that every plaintiff will qualify for government provided insurance. The plaintiff may be too young or have too limited a work history to qualify for Medicare. The victim's injuries may not be severe enough to qualify for a disability exemption to Medicare, which would also require a two year waiting period after qualification for Social Security Disability Insurance (SSDI). Finally, the victim's household income may be too high to qualify for Medicaid.

A final option would be for the plaintiff to purchase private insurance in the individual insurance market. However, under the laws in effect in most states prior to the passage of the ACA, insurers could examine applications for minor errors that could void existing insurance contract ("rescission"), limit annual and lifetime health care expenditures for existing and new customers, and reject applications or deny certain expenditures to any individual with a preexisting condition. The presence of pre-existing injuries from the accident at the heart of any lawsuit/life care plan would typically be enough to prevent plaintiffs from being able to purchase 
an insurance policy in the individual market. All in all, it is reasonable to presume that in the pre-ACA legal setting, victims of accidents would, in many case, be unable to purchase affordable health insurance. Therefore, providing compensation for documented increases in health care costs due to an accident is both reasonable and just.

\section{Insurance and Medical Costs in a Post-ACA World}

Under the Affordable Care Act, three major changes are introduced to health insurance markets. 2 First, the ACA prohibits discrimination based on pre-existing conditions and bans both annual and lifetime expenditure limits. Therefore, under the ACA any victim should be able to purchase health insurance at the same price as any other demographically similar individual regardless of the severity of his or her injuries, the magnitude of expected health care costs, or access to employer provided health insurance. 3 Furthermore, the ACA sets minimum standards for covered services and maximum out-of-pocket expenditures for health insurance plans. The new out-of-pocket limit will be pegged to the Health Savings Account (HSA) limit which is currently $\$ 5,950$ per year for individuals and $\$ 11,900$ for families. Thus, the pre-existing condition provision of the ACA and the quality of insurance requirements serve to limit the annual out-of-pocket costs for medical care for any victim of an accident to a maximum of $\$ 5,950$ plus the cost of a typical health insurance policy in the individual market. This sum may be significantly below the sum of identifiable medical costs in a life care plan.

2 The Kaiser Family Foundation (2011) has prepared a thorough summary of the initiatives and changes legislated in the ACA and is the predominant source for the information provided here.

3 Under ACA, premiums in the new market may only vary by an applicant's age, geographic region, family composition and tobacco use. 
A second major provision of the ACA provides subsidies for insurance premiums and health care costs to those with low income and who do not receive health insurance through the government or a family member's employer. Those whose family income is more than $133 \%$ and less than $400 \%$ of the poverty rate are eligible for significant subsidies that limit the share of income spent on premiums for an insurance policy (ranging from $2 \%$ to $9.5 \%$ of income) and lower limits on out-of-pocket expenditures (one-third to two-thirds of the HSA limit).4 These provisions serve to further cap the expenditures for medical care for any victim of an accident to a sum that may be significantly below the sum of identifiable medical costs in a life care plan before ACA.

The final major piece of the ACA is the individual mandate. This component of the legislation, which is required to prevent adverse selection in the individual policy market, requires that all persons provide proof of adequate insurance, either through their employer, public health insurance, or the individual policy market. Failure to purchase health insurance subjects the individual to a sizable fine. After a transition period between 2014 and 2016, the fine will be set at the greater of $\$ 695$ per person (with a $\$ 2,085$ maximum per family) or 2.5 percent of a household's income. After 2016, the fine minimums will increase with the cost of living. Exemptions to this penalty are granted for a range of reasons including cases where the premium for the lowest cost plan option would exceed eight percent of an individual's income.5 If an individual's expected income is great enough that they would not be exempt, the mandate

4 The ACA included a separate provision to expand Medicaid to individuals with a family income of less than $133 \%$ of the poverty rate. The 2012 United States Supreme Court decision stuck down the requirement that states expand Medicaid in this way or lose current Medicaid funding (Liptak 2012). 
to purchase health insurance implies that he or she would have been required to purchase health insurance absent an accident leading to a tort case. An accident that increases the financial desirability of health insurance does not alter the legal obligation to purchase health insurance.

Given the individual mandate, if the individual purchased health insurance from an individual market before the accident, health insurance costs are the same both before and after the accident since individuals cannot be discriminated against based on health status. Thus, the change in medical care costs would be at most the limit of the out-of-pocket costs for health care plans of $\$ 5,950$ per year. In reality, the losses should also reflect expected annual out-of-pocket health care expenses prior to the accident, making the $\$ 5,950$ per year figure an upper bound for medical care costs. Similarly, any losses of employer provided health insurance due to higher premiums and lack of subsidization on the private market should be compensable in calculations of lost compensation.

If the individual was uninsured prior to the accident, the additional out-of-pocket costs for medical care for any victim of an accident is a maximum of $\$ 5,950$ plus the cost of a typical health insurance policy in the individual market less any government subsidies for the policy, the government imposed fine for not purchasing health insurance, and the medical care costs the individual would have expected absent the accident. In practice, one should expect few persons to not have insurance under the ACA. In Massachusetts, where current health care law has similar provisions to the ACA, the total rate of uninsured is roughly $5 \%$, by far the lowest rate of uninsured in the country (Jones 2012). The Congressional Budget Office (2010) estimates that

5 Other exemptions may be granted based on unspecified financial hardships, religious objections, for American Indians, incarcerated individuals, undocumented immigrants, and those with income below the tax filing threshold. (Kaiser Family Foundation 2011) 
the ACA will increase coverage from the current level of 83 percent to about 95 percent of nonelderly, legal residents in 2021.

Other provisions of the ACA may have a more modest impact on the expected costs of a life care plan. First, the act includes a number of plans to curb the growth of premiums and medical costs. These plans include limits on non-care based expenses for insurers, formal rate increase justification requirements, development of standards to lower administration costs, examining tort reform (though no actual measures to do so), and funding for the development of new wellness and prevention strategies. The ACA also includes new or lower limits on the tax deductibility of medical costs. These measures include a reduction in eligible expenditures and nominal limits for flexible spending accounts, an increase in the threshold of deductible medical expenses from those over 7.5 percent of adjusted gross income to those over ten percent, and an excise tax on "taxable medical devices." One abandoned initiative in the ACA may have further reduced expected costs of a life care plan by providing non-excludable long-term care insurance (the CLASS program). The program was not implemented by the Department of Health and Human Services due to infeasibility. (Sebelius, 2011)

To sum up, there is little reason to believe that most individual's health care costs would be met by health insurance prior to the ACA. Therefore, it is reasonable for life care plans to include provisions for expected health expenditures rather than simply providing plaintiffs money with which to purchase health insurance. When the ACA is fully implemented, however, all individuals will be able to purchase affordable health insurance regardless of the extent of their injuries or their health care and employment status, often with the aid of significant government subsidies. Furthermore, as the ACA requires all individuals to purchase health 
insurance and prevents price discrimination based on health status, most individuals will face identical health insurance costs before and after an accident. Thus, life care costs for medical care should be limited to the legal maximum out-of-pocket expenses allowable under the ACA of $\$ 5,950$ per year.

This finding also suggests a new task for life care planners. As noted previously, under the old health insurance laws the task of the life care planner was to identify any medical and living expenses that are necessary for the victim but would not otherwise have been required in the absence of the accident. Under the ACA, the life care planner also needs to specifically address which health care and living expenses would normally be covered by the minimum insurance requirements mandated by the ACA and which health expenditures are not required to be covered. These requirements may differ from state to state although the ACA mandates certain minimum standards at the federal level as the recent controversy regarding the provision of birth control by health insurers demonstrates.

Finally, the ACA was opposed by some economists and politicians on the grounds that it did not do enough to control costs. Many argued that any significant health insurance bill should include tort reform in order to rein in spiraling health care costs and were critical of the fact that the ACA did not directly address the issue. The idea put forward in this paper, however, suggests that the ACA may well have indirectly resulted in a great deal of tort reform. In many personal injury cases, future medical expenses represent a significant portion of the final damage award. The health insurance reforms contained in the ACA may serve to significantly reduce these damage awards by making affordable health insurance available to injured persons in lieu of expensive tort payments to cover future medical care. 


\section{Caveats}

Though the majority of the initiatives in the ACA were upheld by the Supreme Court in 2012, the ACA is still open to repeal by the federal government. In fact, the Republican Party has made the repeal of the ACA a primary plank of their election campaigns in both 2010 and 2012 (Sack 2010 and Cooper 2012). Though Republican candidates vary on which specific parts of the law they would vote to repeal, the individual mandate is the clearest target. Without the mandate, the guaranteed issue requirement of the ACA would not be economically feasible for health insurers. Therefore, changes to the law may have significant implications for the impact of the ACA on the calculation of the cost of a life plan. Though laws can be changed at any time, the January 1, 2014 implementation date for the individual mandate and the elimination of pre-existing condition restrictions would seem to be an obvious resolution date.

There is also a collateral source issue at play although even here there is reason to believe the ACA changes the underlying reason of excluding collateral source compensation from inclusion in tort cases. Consider the case of privately purchased disability insurance. If disability payments were subtracted from a tort award, the court would essentially be punishing individuals for making prudent insurance decisions regarding future potential loss of income reducing the incentive to properly insure against loss. With health insurance, however, the presumption would be that the overwhelming majority of individuals would purchase health insurance under the ACA, and therefore removing existing health insurance coverage from exclusion under the collateral source rule would not significantly affect health insurance coverage rates reducing the 
economic rationale for having a collateral source rule in place for health insurance. Obviously, this issue remains of significant importance.

\section{Conclusions}

If the ACA is successful in creating open and affordable health care markets that eliminate health restrictions, awards in personal injury cases could be dramatically impacted. First, the goal is to make the person "whole" by providing adequate funding for a life care plan, not to compensate them from their injuries. The funding of health care through private insurance markets is an equally valid way to accomplish this goal if those markets are available to a victim. Second, the individual mandate to purchase health insurance changes the baseline from which one should evaluate what "whole" entails. Specifically, individuals will now either have insurance or be assessed a penalty if they are injured or not. That said, the exemptions as they are currently set remain relatively broad and the future implementation of the law is still in question. In total, the ACA should simplify calculations of the cost of life care plans by limiting costs to that of premiums and out-of-pocket limits less any pre-injury expected medical costs and penalties if uninsured. 


\section{REFERENCES}

Kaiser Family Foundation and Health Research and Education Trust, "Employer Health Benefits: 2007 Annual Survey,” 2007.

Congressional Budget Office, “CBO's Analysis of the Major Health Care Legislation Enacted in March 2010," Congressional Testimony of Douglas W. Elmendorf, CBO Director, March 30, 2011. Available at http://www.cbo.gov/ftpdocs/121xx/doc12119/03-30healthcarelegislation.pdf.

Cooper, Michael, "Platform's Sharp Turn to Right Has Conservatives Cheering," New York Times, August 29, 2012. Accessed at http://www.nytimes.com/2012/08/29/us/politics/republican-platform-takes-turn-to-right.html

Jones, Jeffrey, “Texas Widens Gap Over Other States in Percentage Uninsured," State of the States Blog on Gallup Well-Being Website, March 2, 2012, Accessed at http://www.gallup.com/poll/153053/texas-widens-gap-states-percentage-uninsured.aspx .

Kaiser Family Foundation, "Summary of New Health Reform Law," Focus on Health Reform, April 19, 2011, http://www.kff.org/healthreform/upload/8061.pdf.

Liptak, Adam, "Supreme Court Upholds Health Care Law, 5-4, in Victory for Obama," New York Times, June 29, 2012. Accessed at http://www.nytimes.com/2012/06/29/us/supremecourt-lets-health-law-largely-stand.html?pagewanted=all. 
Martin, Anne, David Lassman, Benjamin Washington, and Aaron Catlin, "Growth in US Health Spending Remaining Slow in 2010; Health Share of Gross Domestic Product Was Unchanged From 2009," Health Affairs, 31(1), 2012, pgs. 208-219.

Sack, Kevin, "Health Care Vote Puts Democrats on Defensive," New York Times, October 27, 2010. Accessed at http://www.nytimes.com/2010/10/27/us/politics/27health.html?pagewanted=all.

Sebelius, Kathleen, “The CLASS Program,” The Health Care Blog, Posted October 14, 2011, http://www.healthcare.gov/blog/2011/10/class10142011.html. 